\title{
Corrigendum
}

\section{Amygdalocortical Circuitry in Schizophrenia: From Circuits to Molecules}

\section{Francine M Benes}

Neuropsychopharmacology (20 I0) 35, 1239; doi:I0.1038/npp.2010.22

Neuropsychopharmacology Reviews (2010) 35, 239-257; doi:10.1038/npp.2009.116; published online 2 September 2009
In this article, the author has made corrections to Figure 5; the revised version follows:

Network association analysis of GAD67 expression and influence of basolateral amygdalar inputs to S. Oriens of sector CA2/3
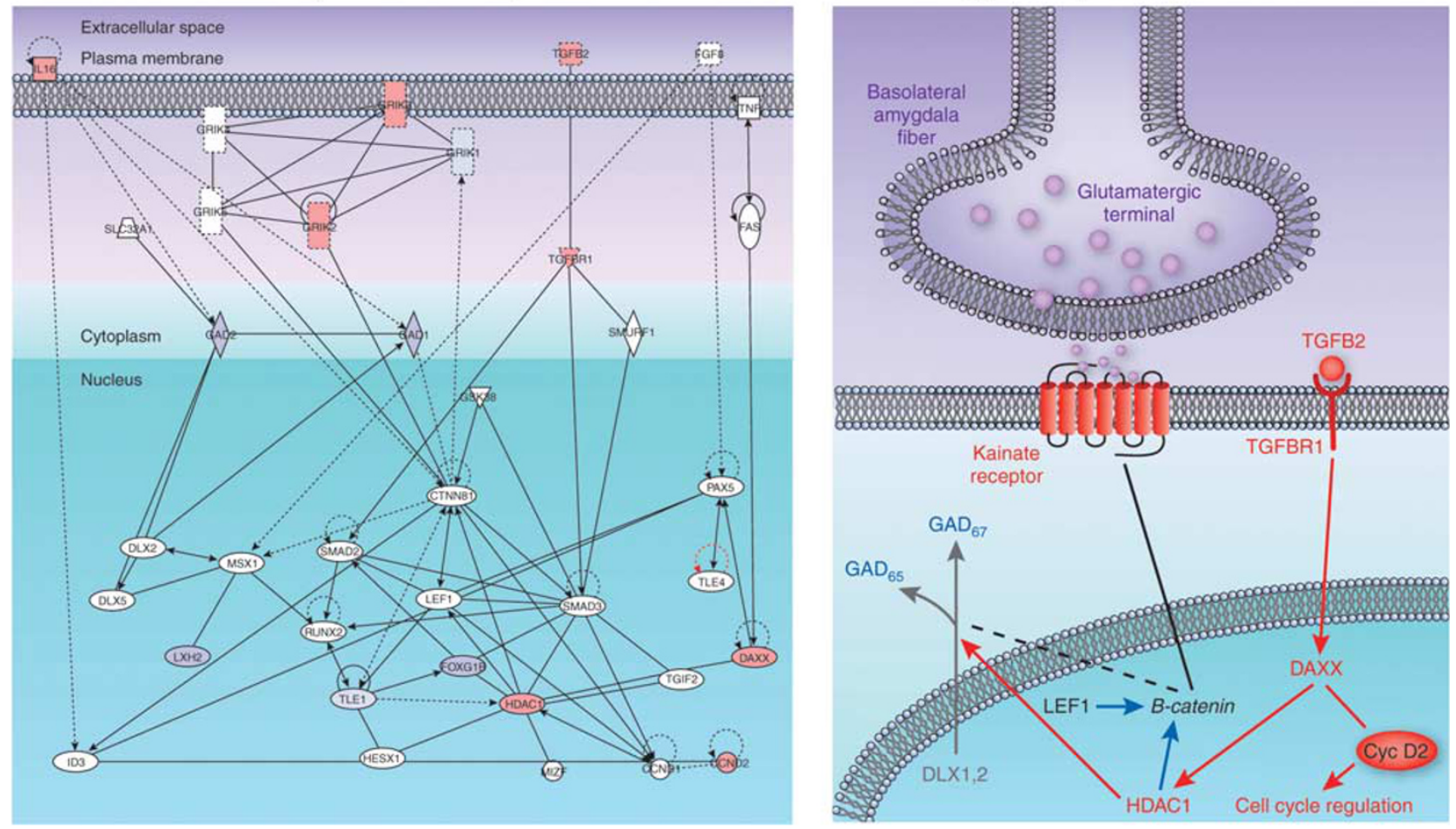